\title{
Antibiotikaresistenz: Tierärzte kämpfen gegen andere Tücken
}

\section{Patrizia Andina}

Dr. med. vet., Wiederkäuermedizin, Gesellschaft Schweizer Tierärztinnen und Tierärzte, Verantwortliche Tierarzneimittel und Tierärztliche Tätigkeiten

\author{
Der Antibiotikaverbrauch in der Tiermedizin sinkt. Weshalb ein gänzlicher Verzicht \\ auf Antibiotika nicht möglich ist, und wo die Herausforderungen einer weiteren \\ Reduktion liegen.
}

Als Ärzte für Tiere haben sich Tierärztinnen und Tierärzte verpflichtet Tiere zu heilen. Im Heimtierbereich kümmern sie sich um enge Begleiter des Menschen. Im Nutztierbereich sind sie verantwortlich für die Lebensmittelsicherheit tierischer Produkte und somit für einen Teil der öffentlichen Gesundheit. In beiden Bereichen kommen sich Tier und Mensch sehr nahe. Das spricht klar dafür, das Problem der Antibiotikaresistenzen gemeinsam anzugehen. Eine spezifische Problematik der Nutztiermedizin besteht darin, dass es sich oft nicht um Erkrankungen bei einzelnen Tieren, sondern um ganze Gruppen handelt. Dies soll das folgende Beispiel aufzeigen.

\section{Bob, das «überzählige» Kalb}

Bob wurde vor 21 Tagen geboren. Er ist das männliche Kalb einer Milchkuh. Wie die meisten seiner Kollegen hat Bob nicht das Zeug zum Zuchtstier und soll deshalb gemästet werden. Wenn der Besitzer ihn in die Mast verkauft, wird er für das feine Milchkuhkalb einen geringen Erlös erzielen, so dass zum Schluss ein Nullsummenspiel resultiert. Aber nur, wenn Bob vorher nicht krank wurde. Denn der finanzielle Aufwand für die Fütterung, Pflege und Haltung entspricht bereits dem Verkaufspreis.

Bob hatte nachts um 2.00 Uhr das Licht der Welt erblickt. Der Landwirt hat die Geburt überwacht. Das Kälbchen hat er aus hygienischen Gründen sofort von der Mutter entfernt und in eine saubere Box gebracht. Danach hat er sich nochmals ins Bett gelegt. Nach dem Melken morgens um 6.00 Uhr hat er Bob das erste Mal Kolostrum gegeben.

\section{Eine andere Plazenta}

Als Wiederkäuer hat Bob von seiner Mutter diaplazentär keine Immunglobulin $\mathrm{G}$ bekommen. Er muss seinen ganzen Bedarf an diesen Antikörpern über das Kolostrum decken. Für Bob kam diese erste Kolostrumgabe zu spät. Bob ist hypogammaglobulinämisch.

\section{Transport und Entwöhnen von nicht immunkompetenten Tieren}

Heute, im Alter von 21 Tagen, muss das Kalb den Geburtsbetrieb bereits verlassen. Es wird von einem Händler abgeholt und zusammen mit anderen Kälbern von anderen Betrieben in einem Lastwagen von Ort zu Ort gefahren, bis es beim Mäster ankommt. Bob wird mit 39 anderen Jungtieren in einem Raum eingestallt. 39 unbekannte Virenstämme treffen auf 39 andere Kälbchen. Einige Kälber leiden bereits an versteckten Infekten wie inneren Nabelabszessen oder Otitiden. Der Mäster impft sie zwar gegen die gängigsten Virenstämme, dennoch erkranken nach fünf Tagen die ersten Kälber so schwer, dass der Bestands-Tierarzt entscheidet, alle Tiere während zehn Tagen antibiotisch gegen Pneumonie zu versorgen (Metaphylaxe). Das Medikament wird über die Milch-Tränkeautomaten verabreicht. Der Tierarzt, mit dem der Mäster eine Vereinbarung hat, hat das Medikament mit einem ausführlichen Rezept verschrieben. Er musste dazu eine vom Bund anerkannte Weiterbildung besuchen und eine Prüfung absolvieren. Alle fünf Jahre muss er die Kenntnisse wiederauffrischen. Der Tierarzt begleitet die Behandlung beim Mäster eng und dokumentiert den Verbrauch der Antibiotika. Einzelne Tiere, die so stark erkrankt sind, dass sie zu wenig trinken, müssen separiert und parenteral behandelt werden.

\section{Schwierige Diagnose}

Das Beispiel mit Bob ist exemplarisch für den Mastkalbbereich. Die Probleme in anderen Nutztierbereichen sind ähnlich gelagert. 


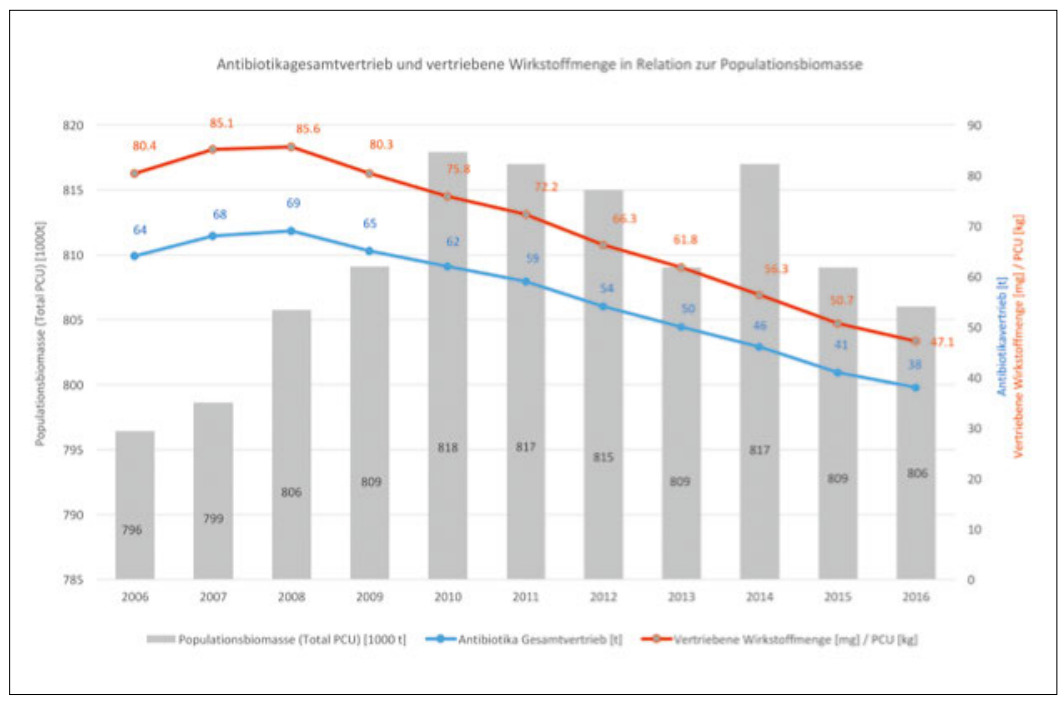

Antibiotikagesamtvertrieb in der Tiermedizin von 2006-2016: Es wird bis anhin nur das gesamte Gewicht aller von Pharmafirmen an Tierärzte in der Schweiz verkauften Antibiotika registriert.

Korrespondenz:

Gesellschaft Schweizer

Tierärztinnen und Tierärzte

(Société des Vétérinaires

Suisses)

Brückfeldstrasse 18

3012 Bern

Tel. 0313073535

info[at]gstsvs.ch
Versuche, die Kälber ohne antibiotische Behandlung einzustallen, scheitern oft. Zur schnellen Sicherung der klinischen Diagnose hat ein Nutztierarzt kaum Möglichkeiten. Es gibt keinen Test, um bei einem Nutztier eine virale von einer bakteriellen Pneumonie kurzfristig zu unterscheiden (analog dem C-reaktiven Protein oder Procalcitonin). Und es gibt keine Krankenkasse, die sich an aufwändigeren Tests finanziell beteiligt. Rinder reagieren bei bakteriellen Pneumonien rasch mit Verwachsungen der Pleuren und Abszessen. Schnelles Reagieren des Tierarztes, oft eben mit der Verschreibung von Antibiotika, ist deshalb unbedingt notwendig, um das Wohl der Tiere zu erhalten.

\section{Engagement der Nutztierärzte}

Die Nutztierärztinnen und Nutztierärzte in der Schweiz leisten einen grossen Effort, den Bedarf von Antibiotika in den Tierhaltungen zu reduzieren. Eine einfache Lösung gibt es nicht; verschiedenste Massnahmen wurden deshalb umgesetzt oder initiiert. Einen Schwerpunkt bildet die Beratung der Tierhalter. Es gilt, präventive Massnahmen durchzusetzen und die Haltung zu optimieren. Im Beispiel von Bob hiesse dies, dass die Kolostrumgabe und die Impfprogramme optimiert würden. Zudem ist als weiterer Schwerpunkt sicherzustellen, dass die Diagnostik finanziell tragbar ist und der nachhaltige Nutzen für den Tierhalter aufgezeigt werden kann. Tiergesundheitsdienste leisten schon seit mehreren Jahren wertvolle Dienste für die Tiergesundheit, indem sie als Vereinigung von Spezialisten mit Schwerpunkt Prävention und Management den Tierhaltern und den Tierärzten Unterstützung anbieten. Ein Kälbergesundheitsdienst befindet sich derzeit im Aufbau.

In Zusammenarbeit mit dem Bund und im Rahmen der nationalen Strategie gegen Antibiotikaresistenzen (StAR) werden mit Stakeholdern weitere Massnahmen diskutiert. So hat die Tierärzteschaft Therapieleitlinien für den Nutztierbereich entwickelt. Ab 2019 sollen die Tierärztinnen und Tierärzte jeden Antibiotikaeinsatz (auch im Heimtierbereich) in einer Bundesdatenbank eingeben (Heilmittelgesetz und Verordnung IS-ABV). Durch diese Daten soll aufgezeigt werden, wo am häufigsten mit Antibiotika behandelt wird. Dies macht es wiederum möglich, gezielt zu beraten und zu informieren.

Eine Entschärfung des beschriebenen Problems könnte auch über die vermehrte Ausmast der Kälber auf dem Geburtsbetrieb erreicht werden. Die zeit- und kostenintensive Betreuung der jungen Kälber so früh wie möglich auszulagern, ist aber heute üblich und eine Folge des Kostendrucks in der Landwirtschaft. Eine Änderung dieses Systems bedingt ein Umdenken in der Landwirtschaft, aber auch bei den Vermarktern und in der Gesellschaft. Die Preise für die entsprechenden Produkte würden vermutlich steigen. Keine Lösung ist, dass «überzählige» Kälber wie Bob nach der Geburt umgehend getötet oder zur Mast ins Ausland abgeschoben werden. Wir müssen dieses Problem in der Schweiz lösen.

Eine Tieraufzucht, die ohne Antibiotikagabe auskommt, wird nicht möglich sein. Die Tierärzteschaft arbeitet jedoch intensiv daran, dass Antibiotika nur gezielt eingesetzt werden, nämlich wenn es zwingend erforderlich ist, und dass Antibiotikaeinsätze weniger oft nötig sind. Die Antibiotikastatistik im Tierbereich zeigt, dass wir auf dem richtigen Weg sind.

Bildnachweis

BLV 